\title{
Sodium Lauryl Sulfate Stimulates the Generation of Reactive Oxygen Species through Interactions with Cell Membranes
}

\author{
Taeko Mizutani ${ }^{1 *}$, Ryota Mori ${ }^{1}$, Misaki Hirayama ${ }^{1}$, Yuki Sagawa ${ }^{1}$, Kenji Shimizu², \\ Yuri Okano ${ }^{1}$ and Hitoshi Masaki ${ }^{1}$ \\ ${ }^{1}$ Tokyo University of Technology - School of Bioscience and Biotechnology. 1404-1, Katakura-machi, Hachioji-shi, Tokyo 192-0982, JAPAN \\ ${ }^{2}$ NIKKOL Group Cosmos Technical Center Co. Ltd., 3-24-3, Hasune, Itabashi-ku, Tokyo 174-0046, JAPAN
}

\begin{abstract}
Sodium lauryl sulfate (SLS), a representative anionic surfactant, is well-known to induce rough skin following single or multiple topical applications. The mechanism by which SLS induces rough skin is thought to result from the disruption of skin moisture function consisting of NMF and epidermal lipids. However, a recent study demonstrated that topically applied SLS easily penetrates into the living cell layers of the epidermis, which suggests that physiological alterations of keratinocytes might cause the SLS-induced rough skin. This study was conducted to clarify the effects of SLS on keratinocytes to demonstrate the contribution of SLS to the induction of rough skin. In addition, the potentials of other widely used anionic surfactants to induce rough skin were evaluated. HaCaT keratinocytes treated with SLS had increased levels of intracellular ROS and IL-1 $\alpha$ secretion. Application of SLS on the surface of a reconstructed epidermal equivalent also showed the increased generation of ROS. Further, SLS-treated cells showed an increase of intracellular calpain activity associated with the increase of intracellular $\mathrm{Ca}^{2+}$ concentration. The increase of intracellular ROS was abolished by the addition of BAPTA-AM, a specific chelator of $\mathrm{Ca}^{2+}$. In addition, IL-1 $\alpha$ also stimulated ROS generation by HaCaT keratinocytes. An ESR spin-labeling study demonstrated that SLS increased the fluidity of membranes of liposomes and cells. Together, those results indicate that SLS initially interacts with cell membranes, which results in the elevation of intracellular $\mathrm{Ca}^{2+}$ influx. $\mathrm{Ca}^{2+}$ stimulates the secretion of IL-1 $\alpha$ due to the activation of calpain, and also increases ROS generation. IL-1 $\alpha$ also stimulates ROS generation by HaCaT keratinocytes. We conclude from these results that the elevation of intracellular ROS levels is one of the causes of SLS-induced rough skin. Finally, among the other anionic surfactants tested, sodium lauryl phosphate has less potential to induce rough skin because of its lower generation of ROS.
\end{abstract}

Key words: SLS, ROS, IL- $1 \alpha, \mathrm{Ca}^{2+}$, fluidity

\section{INTRODUCTION}

Water in the stratum corneum is fundamental and is critical to the maintenance of healthy skin. In the stratum corneum, water retention at an adequate level depends on corneocytes, natural moisturizing factor $(\mathrm{NMF})$ and lamellar structures of intercellular lipids consisting of ceramides, cholesterol and free fatty acids ${ }^{1,2}$. The loss of water content initially causes dry skin and eventually results in rough skin. Rough skin is generally characterized by alterations of morphology, which is called as "kime" in Japanese, the appearance of much scaling on the surface of the skin while dry skin is characterized by low water content and high levels of trans-epidermal water loss (TEWL). Parameters of corneocytes collected from rough skin indicated elevations in the ratio of IL- $1 \alpha$ receptor antagonist and IL- $1 \alpha^{3)}$ and the level of carbonylated proteins in the stratum corneum ${ }^{4}$. These facts indicate that sub-erythemal inflammation in the skin is caused by the excess secretion of IL- $1 \alpha$, which is a pro-inflammatory cytokine, and by the generation of excess reactive oxygen species (ROS) in cells. Furthermore, an epidemiological survey reported a negative correlation between carbonylated proteins in the stratum corneum and skin moisture function composed of water holding capacity and TEWL ${ }^{5)}$. Carbonylated proteins

\footnotetext{
*Correspondence to: Taeko Mizutani, Tokyo University of Technology - School of Bioscience and Biotechnology. 1404-1, Katakura-machi, Hachioji-shi, Tokyo 192-0982, JAPAN

E-mail: g12110085b@edu.teu.ac.jp

Accepted July 28, 2016 (received for review March 28, 2016)

Journal of Oleo Science ISSN 1345-8957 print / ISSN 1347-3352 online

http://www.jstage.jst.go.jp/browse/jos/ http://mc.manusriptcentral.com/jjocs
} 


\section{T. Mizutani, R. Mori and M. Hirayama et al.}

are oxidized proteins produced by reactions between free amino residues of proteins and reactive aldehyde compounds yielded by lipid peroxidation ${ }^{6)}$. The sum of these facts suggest that excessive oxidative stress is one of the critical causes of rough skin.

Japanese consumers prefer to clean their face and body often, and therefore, they use detergents, such as hand soaps, body soaps and facial cleansers, at a high frequency compared with foreigners. Since most detergents are formulated using anionic surfactants as their active ingredients, this indicates that Japanese are more influenced by anionic surfactants in the skin than are foreigners. In fact, we used the topical application of SLS, a representative anionic surfactant, to create an in vivo model for skin roughness ${ }^{7)}$. Thus, there is a high possibility that the excess use of detergents induces rough skin.

On the other hand, it has been suggested that there is a relationship between rough or dry skin and sensitive skin. In general, sensitive skin is defined as skin having a higher susceptibility to sensory irritation ${ }^{8)}$. Furthermore, sensory irritations, such as stinging, itching and tingling, are recognized due to the excitement of nerve c-fibers by the stimulation of some chemicals ${ }^{9)}$. A recent study reported that the disruption of barrier function by applying acetoneether recruits the nerve tips of c-fibers into the epidermis triggering an imbalance between NGF, a nerve development factor, and Semaphorin 3A, a factor that suppresses nerve development ${ }^{10)}$. That result points to the possibility that skin dryness increases the susceptibility to sensory irritation. Regarding differences between races on the susceptibility to sensory irritation, an epidemiological study indicated that Japanese women have a lower threshold concentration on the perception of a stinging inducing chemical than do German women ${ }^{11)}$. This suggests that the difference originates from different habits like washing.

The mechanism of detergent-induced rough skin is understood to result from a loss of skin moisture related substances such as NMF and epidermal lipids due to their extraction with surfactants ${ }^{12,13)}$. In fact, the topical application of SLS, which is a representative detergent, causes skin irritation associated with alterations of epidermal differentiation comprising the down-regulation of profilaggrin and the desquamation-related enzymes, kallikreins 5 and $7^{14)}$. However, since a confocal Raman microscopic study reported that SLS penetrates into the skin ${ }^{15)}$, it has been considered a possibility that the direct action of SLS on keratinocytes triggers the rough skin. Many studies regarding the direct actions of SLS on keratinocytes have been reported, and have demonstrated that SLS causes irritation due to the excess production of two inflammatory mediators, IL-1 and PGE2, by keratinocytes ${ }^{16)}$. Also, an in vivo study demonstrated that the topical application of SLS increases the mRNA levels of IL-1alpha in the epidermis ${ }^{17)}$. Thus, in an alternative test registered as OECD 439 to predict the potential of skin irritants, SLS is employed as a positive control, and cell viability and IL-1 $\alpha$ secreted into the medium of reconstructed epidermal equivalents after samples are applied topically are accepted as parameters for assessing skin irritation. However, it is still unclear how the induction is caused by SLS directly and what substances are mediated by that induction. In general, it is known that low humidity promotes skin dryness and ultimately results in skin roughness. A recent study has reported that carbonylated proteins are observed in corneocytes of dry skin in the winter season ${ }^{4}$. That fact was hypothesized to contribute to oxidative stress in the development of skin roughness, because carbonylated proteins are end-products of lipid peroxidation initiated by $\operatorname{ROS}^{6,18)}$.

Thus, in order to clarify the mechanism of anionic surfactant-induced rough skin, we examined the cellular responses of keratinocytes exposed to the anionic surfactant SLS, focusing on intracellular ROS levels. In addition, we evaluated the potentials of other anionic surfactants that are widely used in detergents to induce rough skin using the cellular responses identified in this study.

\section{EXPERIMENTAL}

\subsection{Reagents}

Dulbecco's modified Eagle medium (DMEM) and Hanks' balanced salt solution with $\mathrm{Ca}^{2+}$ and $\mathrm{Mg}^{2+}$ (HBSS) was obtained from Nissui Pharmacy (Tokyo, Japan) and fetal bovine serum (FBS) was obtained from Invitrogen (Carlsbad, CA, USA). The BCA protein assay kit was purchased from Pierce Chemical Co. (Rockford, IL, USA). Suc-LLVY7-aminomethylcoumarin (Suc-LLVY-AMC) was obtained from Boston Biochem(Boston, MA, USA). BAPTA-AM (1,2-bis (o-aminophenoxy) ethane-N,N,N',N'-tetraacetic acid) acetoxymethyl ester, 5- doxyl stearic acid, Fura 2-AM and 2'.7'-dichlorodihydrofluorescin diacetate $\left(\mathrm{H}_{2} \mathrm{DCHFDA}\right)$ were purchased from Sigma (St Louis, MO, USA). MCLA (6(4-Methoxyphenyl)-2-methyl-3,7-dihydroimidazo-[1,2-a pyrazin-3-one hydrochloride) was obtained from Tokyo Chemical Industry(Tokyo, Japan). IL-1 $\alpha$ and IL-1 $\alpha$ ELISA Quantikine kits were purchased from R\&D Systems (Minneapolis, MN, USA). MitoSox was purchased from Molecular Probes (Eugene, OR, USA) . RHE models (a reconstructed human epidermal equivalent) were purchased from Episkin(Lyon, France). SLS, lecithin from soybean and cholesterol was purchased from Nacalai Tesque (Kyoto, Japan). Sodium lauryl ether sulfate, sodium polyoxyethylene(5) lauryl ether carboxylate, sodium polyoxyethylene (11) lauryl ether carboxylate, sodium lauryl phosphate, lauryl ether phosphate, sodium lauroyl methyl alanine, sodium lauroyl methyl taurine, sodium laurate, potassium cocoate and potassium myristate were kind gifts from Nikko Chemicals (Tokyo, Japan). 


\section{SLS generates ROS through interactions with cell membranes}

\subsection{Cell culture}

HaCaT keratinocytes ${ }^{19)}$ were cultured in DMEM with 5\% FBS at $37^{\circ} \mathrm{C}$ in a humidified atmosphere containing $5 \%$ $\mathrm{CO}_{2}$.

\subsection{Intracellular ROS}

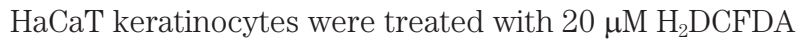
in HBSS for $30 \mathrm{~min}$. After washing with HBSS, cells were cultured with DMEM containing various concentrations of SLS and 5\% FBS for $24 \mathrm{~h}$. After lysing the cells with $0.1 \%$ Triton X-100 in PBS, the fluorescence (Ex; 485 nm, Em; $530 \mathrm{~nm}$ ) was measured with a Spectra Max Gemini fluorescence micro-plate reader (Molecular Devices, CA, USA). Intracellular ROS levels are calculated as fluorescence intensity (F.I.) per $\mu \mathrm{g}$ protein and are expressed as a fold change of the value of control cells. Protein concentrations were determined with a BCA protein assay kit.

\subsection{Mitochondrial ROS}

HaCaT keratinocytes were treated with $5 \mu \mathrm{M}$ MitoSOX in HBSS for 30 min. After washing with HBSS, cells were incubated with HBSS containing various concentrations of SLS for several periods. After lysing the cells with $0.1 \%$ Triton X-100 in PBS, the fluorescence(Ex: 510 nm, Em: $580 \mathrm{~nm}$ ) was measured with a Spectra Max Gemini fluorescence micro-plate reader. Mitochondrial ROS levels are calculated as fluorescence intensity(F.I.) per $\mu$ g protein and are expressed as a fold change of the value of control cells. Protein concentrations were determined with a BCA protein assay kit.

\subsection{ROS in a reconstructed human epidermal equivalent (RHE model)}

SLS in PBS $(150 \mu \mathrm{L})$ at various concentrations was placed on the surface of RHE models for 15 min. After washing with PBS, chemiluminescence images were taken immediately after washing (15 min after) and $19 \mathrm{~h}$ after washing. MCLA, which generates chemiluminescence by reaction with superoxide anion radicals and singlet oxygen ${ }^{20)}$, was used as a chemiluminescence probe. $100 \mu \mathrm{M}$ MCLA prepared with $50 \% \mathrm{EtOH}$ in $\mathrm{PBS}(100 \mu \mathrm{L})$ was placed on the surface of the RHEs, and chemiluminescence images were taken with a NightOWL(Berthold Technologies, Bad Wildbad, Germany) from the epidermis site.

\subsection{IL-1 $\alpha$ secretion}

HaCaT keratinocytes were cultured in DMEM containing various concentrations of SLS and 5\% FBS for several periods. IL- $1 \alpha$ secreted into the medium was quantified using an IL-1 $\alpha$ ELISA Quantikine kit. Protein concentrations were determined using the BCA protein assay kit to allow calculation of the data as a quantitative value per mg protein.

\subsection{Calpain activity}

$\mathrm{HaCaT}$ keratinocytes were exposed to SLS at $50 \mu \mathrm{g} / \mathrm{mL}$. At several points after SLS exposure, cells were treated with $10 \mu \mathrm{M}$ Suc-LLVY-AMC ${ }^{21)}$ for $1 \mathrm{~h}$. After lysing with $0.1 \%$ Triton X-100, the fluorescence intensity (Ex: $380 \mathrm{~nm}, \mathrm{Em}$ : $460 \mathrm{~nm}$ ) of each lysate that originated from AMC was measured with Spectra Max Gemini fluorescence micro-plate reader. AMC levels were quantified using a calibration curve. Protein concentrations were determined using the BCA protein assay kit to allow calculation of the data as intensity per unit protein. Calpain activity is expressed as

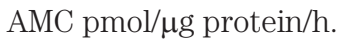

\subsection{Intracellular $\mathrm{Ca}^{2+}$}

After loading with $10 \mu \mathrm{M}$ Fura 2-AM ${ }^{22)}$, HaCaT keratinocytes were exposed to SLS in HBSS at a concentration of $50 \mu \mathrm{g} / \mathrm{mL}$. The fluorescence (Ex: $340 \mathrm{~nm}$, Em: $510 \mathrm{~nm}$ ) was measured with a Spectra Max Gemini fluorescence microplate reader. Intracellular $\mathrm{Ca}^{2+}$ is calculated as fluorescence intensity (F.I.) per $\mu$ g protein and is expressed as a fold change of the value of control cells. Protein concentrations were determined with a BCA protein assay kit.

\subsection{Membrane fluidity using ESR spin-labeling}

Alterations in membrane fluidity of liposomes and HaCaT keratinocytes were estimated using an ESR spin-labeling method ${ }^{23)}$ with 5-doxyl stearic acid (5-DSA) as an ESR spin-labeling agent ${ }^{24)}$. Liposomes were prepared with lipids in which lecithin and cholesterol were mixed in a lipid ratio of 2:1, as previously detailed ${ }^{25)}$. Liposomes and HaCaT keratinocytes $\left(1.0 \times 10^{6}\right.$ cells $)$ were incubated with 1 $\mathrm{mM}$ 5-DSA and $10 \mathrm{mM}$ 5-DSA, respectively, to incorporate the spin-labeling agent into the membrane region. To estimate the effects of SLS on membrane fluidity, the order parameter (S) of the cells in the presence of SLS was calculated from the ESR spectra using the following equation:

$\mathrm{S}=(\mathrm{A} / /-\mathrm{A} \perp) /[\mathrm{Azz}-1 / 2(\mathrm{Axx}+\mathrm{Ayy})]($ Axx: $0.63 \mathrm{mT}$ Ayy: $0.58 \mathrm{mT}$ Azz: $3.36 \mathrm{mT}$ )

ESR spectra were obtained with a RFR-30 spectrometer (Tokyo, Japan) at $37^{\circ} \mathrm{C}$ under the following conditions: modulation frequency, $100 \mathrm{kHz}$; modulation amplitude width, $0.1 \mathrm{mT}$; scanning field, $338.1 \pm 5 \mathrm{mT}$; receiver gain, 200; response time, 0.03; sweep time, $8 \mathrm{~min}$; and output power, $4 \mathrm{~mW}$.

\section{RESULTS}

\subsection{ROS generation in SLS-exposed HaCaT keratino-} cytes and a RHE model

Intracellular ROS levels were evaluated using two different probes, $\mathrm{H}_{2}$ DCFDA and MitoSox. When using $\mathrm{H}_{2}$ DCFDA as a fluorescence probe to detect $\mathrm{H}_{2} \mathrm{O}_{2}$, SLS gave a dosedependent increase of intracellular ROS levels for a $24 \mathrm{~h}$ 


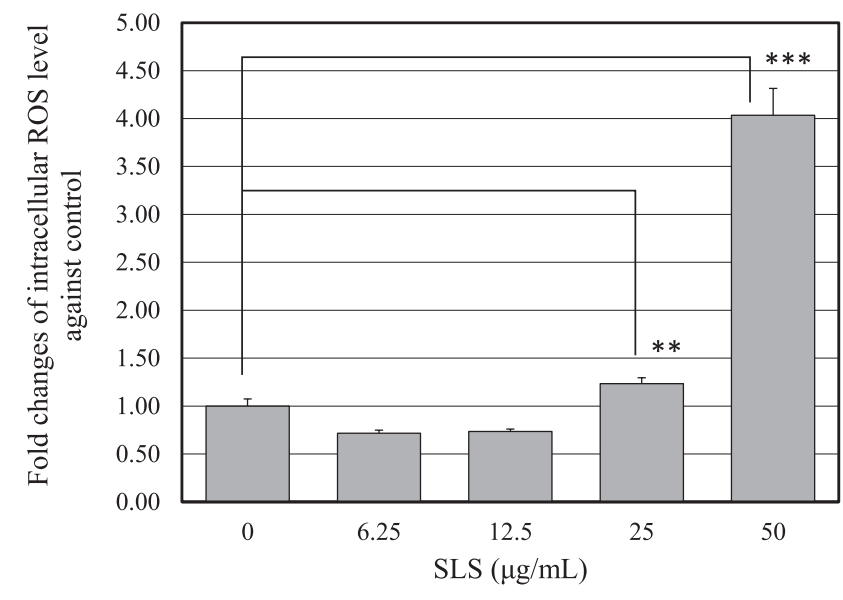

Fig. 1 Intracellular ROS levels in SLS-treated HaCaT keratinocytes.

HaCaT keratinocytes loaded with $20 \mu \mathrm{M} \mathrm{H}_{2} \mathrm{DCFDA}$ were cultured in DMEM containing various concentrations of SLS and 5\% FBS for $24 \mathrm{~h}$. The fluorescence (Ex: 485 nm, Em: 530 nm) of cell lysates with $0.1 \%$ Triton X-100 in PBS was measured. Intracellular ROS levels are calculated as fluorescence intensity (F.I.) per $\mu$ g protein. Protein concentrations were determined with a BCA protein assay kit. Data are expressed as averages and standard deviations of a fold change against the value of control cells $(n=5)$. Significance; Student t-test, $* * p<0.01$, *** $p<$ 0.001 .

exposure. For instance, SLS at $50 \mu \mathrm{g} / \mathrm{mL}$ showed an increase of $4.03 \pm 0.28$ fold (Fig. 1). Focusing on mitochondria, SLS significantly increased ROS generation to $10.1 \pm$ 0.6 fold in mitochondria even at $1 \mathrm{~h}$ exposure (Fig. 2). To identify whether SLS actually reaches the living cells and stimulates ROS generation, SLS was topically applied on the surface of RHE models. ROS generation was then assessed by taking chemiluminescence images with the NightOWL. SLS stimulated ROS generation even at 15 min after the application. Furthermore, the ROS generation of the RHE model treated with SLS was detected at 19 h(Fig. 3).

\subsection{IL-1 $\alpha$ secretion of SLS-exposed HaCaT keratinocytes}

In order to determine the relationship between ROS generation and IL-1 $\alpha$, the secretion profile of IL- $1 \alpha$ after exposure of HaCaT keratinocytes to SLS was examined. The secretion of IL-1 $\alpha$ was potently increased at $24 \mathrm{~h}$, however it was not detected at 6 h (Fig. 4a). Generally, IL- $1 \alpha$ is stored in cells as a precursor, pro-IL-1 $\alpha$. To secrete IL- $1 \alpha$, processing by calpain, which is a $\mathrm{Ca}^{2+}$ dependent protease, is required ${ }^{26)}$. The intracellular calpain activity showed significant increases in a time-dependent manner after SLS exposure (Table 1).

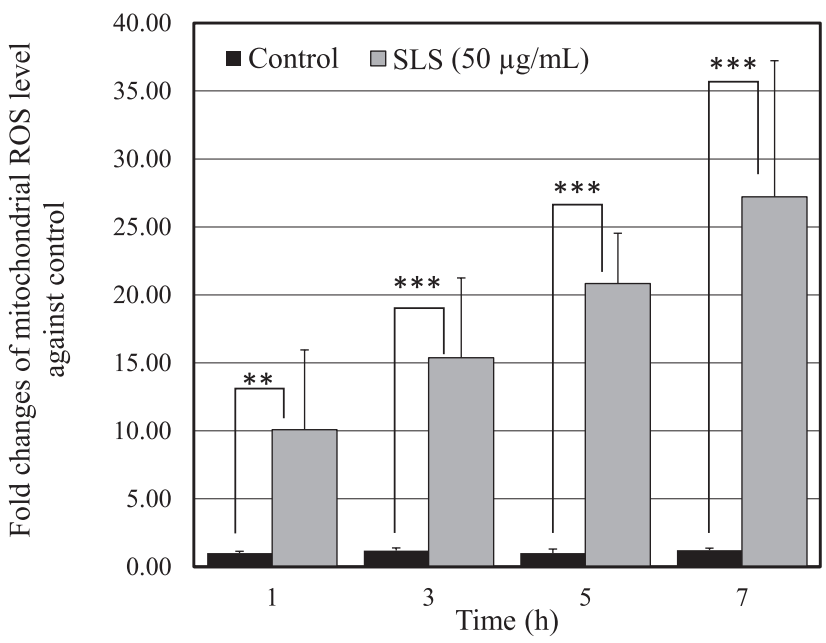

Fig. 2 Mitochondrial ROS levels in SLS-treated HaCaT keratinocytes.

HaCaT keratinocytes loaded with $5 \mu \mathrm{M}$ MitoSOX were incubated with HBSS containing various concentrations of SLS for several periods. The fluorescence (Ex: 510 nm, Em: 580 nm) of cell lysates with $0.1 \%$ Triton X-100 in PBS was measured. Mitochondrial ROS levels are calculated as fluorescence intensity (F.I.) per $\mu$ g protein. Protein concentrations were determined with a BCA protein assay kit. Data are expressed as averages and standard deviations of a fold change against the value of control cells $(n=5)$. Significance; Student t-test, $* * p<0.01$, *** $p<$ 0.001 .

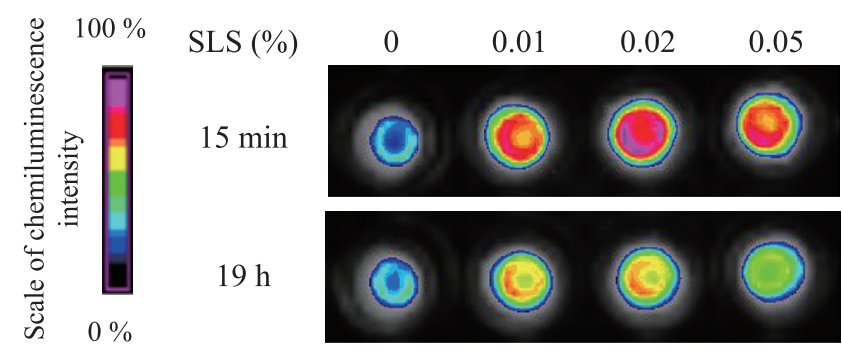

Fig. 3 Chemiluminescence images of SLS-treated RHE models.

SLS in PBS $(150 \mu \mathrm{L})$ at various concentrations was placed on the surface of RHE models for $15 \mathrm{~min}$. After washing with PBS, $100 \mu \mathrm{M}$ MCLA prepared with $50 \%$ EtOH in $\mathrm{PBS}(100 \mu \mathrm{L})$ were placed on the surface of the RHEs. Chemiluminescence images were taken with a NightOWL at $15 \mathrm{~min}$ and at $19 \mathrm{~h}$. 
(a)

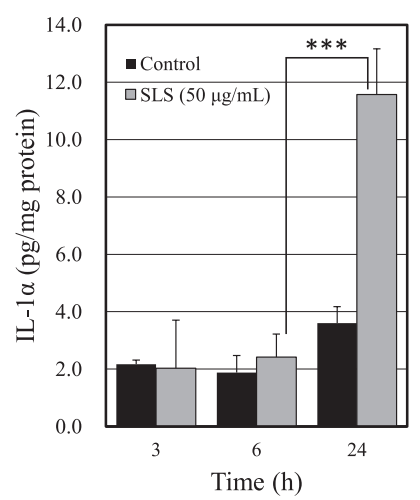

(b)

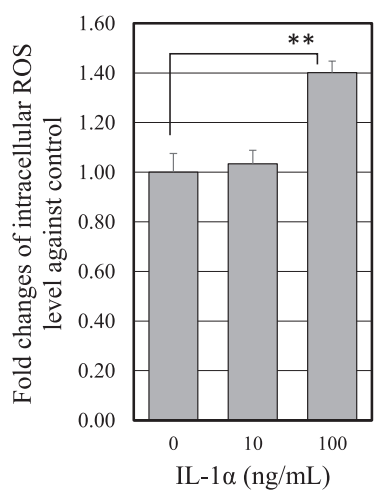

Fig. 4 IL-1 $\alpha$ secretion of SLS-treated HaCaT keratinocytes and ROS generation of IL-1 $\alpha$-treated HaCaT keratinocytes.

a) HaCaT keratinocytes were cultured in the presence of SLS at a concentration of $50 \mu \mathrm{g} / \mathrm{mL}$ for various periods. IL- $1 \alpha$ secreted into medium was quantified using an IL-1 $\alpha$ ELISA Quantikine kit. Protein concentrations were determined using a BCA protein assay kit. Data are expressed as quantitative value (pg) per mg protein. b) HaCaT keratinocytes loaded with $20 \mu \mathrm{M} \mathrm{H}_{2}$ DCFDA were cultured in the presence of IL- $1 \alpha$ at 10 and $100 \mathrm{ng} /$ $\mathrm{mL}$ for $24 \mathrm{~h}$. The fluorescence (Ex: $485 \mathrm{~nm}$, Em: $530 \mathrm{~nm}$ ) of cell lysates with $0.1 \%$ Triton X-100 in PBS was measured. Intracellular ROS levels are calculated as fluorescence intensity (F.I.) per $\mu \mathrm{g}$ protein. Protein concentrations were determined with a BCA protein assay kit. Data are expressed as averages and standard deviations of a fold change against the value of control cells $(n=5)$. Significance; Student t-test, $* * p<0.01$, *** $p<$ 0.001 .

\subsection{Involvement of IL-1 $\alpha$ on ROS generation}

To address the involvement of IL-1 $\alpha$ on ROS generation in HaCaT keratinocytes, intracellular ROS levels of HaCaT keratinocytes cultured in the presence of IL-1 $\alpha$ were measured. IL- $1 \alpha$ at a concentration of $100 \mathrm{ng} / \mathrm{mL}$ elevated the intracellular ROS level 1.4 fold (Fig. 4b).

\subsection{Intracellular $\mathrm{Ca}^{2+}$ levels and ROS generation}

Intracellular $\mathrm{Ca}^{2+}$ levels were estimated with the fluorescence intensity of Fura-2. After loading with Fura-2 AM, HaCaT keratinocytes were exposed to SLS at a concentration of $50 \mu \mathrm{g} / \mathrm{mL}$. The fluorescence intensity per $\mu \mathrm{g}$ protein of SLS-treated cells showed an increase to $3.2 \pm 2.0(p<$ 0.001 ) at $3 \mathrm{~h}$ after treatment (Fig. 5a). Further examination was conducted to clarify the involvement of $\mathrm{Ca}^{2+}$ on ROS generation in SLS-exposed cells. BAPTA, which is a specific chelator of $\mathrm{Ca}^{2+27)}$, suppressed intracellular ROS levels. The results indicate the involvement of $\mathrm{Ca}^{2+}$ on ROS gen-

Table 1 Calpain activity of SLS-treated HaCaT keratinocytes.

\begin{tabular}{ccc}
\hline \multirow{2}{*}{ Time $(\mathrm{h})$} & \multicolumn{2}{c}{ AMC $(\mathrm{pmol} / \mu \mathrm{g}$ protein $/ \mathrm{h})$} \\
\cline { 2 - 3 } & Control & SLS \\
\hline 1 & ND & ND \\
3 & ND & $0.20 \pm 0.19$ \\
5 & ND & $1.40 \pm 0.67$ \\
7 & ND & $2.27 \pm 1.21$ \\
9 & ND & $3.65 \pm 1.04$ \\
24 & $0.70 \pm 0.37$ & $21.62 \pm 4.45^{* * *}$ \\
\hline
\end{tabular}

$\mathrm{HaCaT}$ keratinocytes were exposed to SLS at $50 \mu \mathrm{g} / \mathrm{mL}$ At several times after SLS exposure, cells were treated with $10 \mu \mathrm{M}$ Suc-LLVYAMC for $1 \mathrm{~h}$. After lysing with $0.1 \%$ Triton $\mathrm{X}-100$, the fluorescence (Ex: $380 \mathrm{~nm}, \mathrm{Em}$ : $460 \mathrm{~nm}$ ) of each lysate was measured. Protein concentrations were determined using a BCA protein assay kit to allow calculation of the data as intensity per unit protein. Calpain activity is expressed as AMC $\mathrm{pmol} / \mu \mathrm{g}$ protein/h. ND: not detected. Significance; Student t-test $* * * p<$ 0.001 .

eration by SLS (Fig. 5b).

\subsection{Interaction of SLS with cell membranes}

The fluidity of cell membranes was measured using the ESR spin labeling method with 5-DSA as the spin labeling probe. The order parameters of liposomes and HaCaT keratinocytes treated with SLS exhibited lower values than that of SLS-untreated controls (Table 2). These results indicate that SLS interacts with membranes and results in increased membrane fluidity.

\subsection{Evaluation of anionic surfactants on the potential to induce rough skin}

The abilities of widely used anionic surfactants on ROS generation and IL-1 $\alpha$ secretion are summarized in Table 3. Among the anionic surfactants tested, SLS showed the highest values both for ROS generation and for IL-1 $\alpha$ secretion. On the other hand, sodium lauryl phosphate did not increase ROS generation or IL-1 $\alpha$ secretion.

\section{DISCUSSION}

In this study, SLS stimulated intracellular ROS levels of HaCaT keratinocytes and of RHE models. The ROS generation in the RHE model indicates that SLS promptly reaches the region of living cells though the stratum corneum and stimulates ROS generation even at 15 min after application. 
T. Mizutani, R. Mori and M. Hirayama et al.

(a)

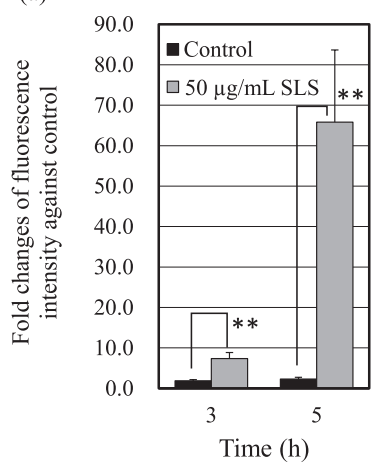

(b)

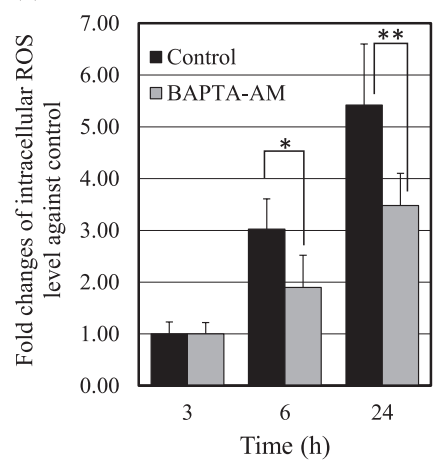

Fig. $5 \mathrm{Ca}^{2+}$ influx of SLS-treated HaCaT keratinocytes and effects of a $\mathrm{Ca}^{2+}$ chelator, BAPTA-AM, on SLSinduced ROS generation.

a) HaCaT keratinocytes were loaded with $10 \mu \mathrm{M}$ Fura 2-AM and were exposed to SLS in HBSS at a concentration of $50 \mu \mathrm{g} / \mathrm{mL}$. The fluorescence(Ex: 340 nm, Em: 510 nm) was measured with a fluorescence micro-plate reader. Intracellular $\mathrm{Ca}^{2+}$ is calculated as fluorescence intensity(F.I.)per $\mu \mathrm{g}$ protein and is expressed as fold change of the value of control cells. Protein concentrations were determined with a BCA protein assay kit. b) HaCaT keratinocytes were loaded with $20 \mu \mathrm{M} \mathrm{H} \mathrm{H}_{2} \mathrm{DCFDA}$ and then were cultured with various concentrations of SLS with or without BAPTA-AM $(25 \mu \mathrm{M})$ for $24 \mathrm{~h}$. The fluorescence (Ex: $485 \mathrm{~nm}$, Em: $530 \mathrm{~nm}$ ) of cell lysates with $0.1 \%$ Triton X-100 in PBS was measured. Intracellular ROS levels are calculated as fluorescence intensity (F.I.) per $\mu \mathrm{g}$ protein. Protein concentrations were determined with a BCA protein assay kit. Data are expressed as averages and standard deviations of a fold change against the value of control cells $(n=5)$. Significance; Student t-test $* p<0.05$, ** $p<0.01$.

In examinations of HaCaT keratinocytes, SLS elicits ROS generation due to the stimulation of mitochondria, and finally increases ROS levels in cells. In addition, SLS enhances the secretion of IL- $1 \alpha$ associated with the activation of intracellular calpain. Furthermore, since IL- $1 \alpha$ also increases intracellular ROS levels, the ROS generation of SLS might be further stimulated by IL-1 $\alpha$. Regarding ROS generation, a $\mathrm{Ca}^{2+}$ specific chelator, BAPTA ${ }^{27)}$, suppresses ROS generation of SLS-exposed HaCaT keratinocytes. These results indicate that $\mathrm{Ca}^{2+}$ is one initiator of ROS generation. In general, the intracellular $\mathrm{Ca}^{2+}$ concentration is regulated by release from the endoplasmic reticulum, where $\mathrm{Ca}^{2+}$ is stored in vesicles ${ }^{28)}$, and by $\mathrm{Ca}^{2+}$ channels located at the cell membrane ${ }^{29)}$. In the case of SLS, it was speculated that the non-specific influx of $\mathrm{Ca}^{2+}$ ions through the cell membrane contributes to the increase of intracellular $\mathrm{Ca}^{2+}$ concentrations due to the interaction of SLS with cell
Table 2 Membrane fluidities of SLS-treated liposomes and HaCaT keratinocytes.

\begin{tabular}{lcrl}
\hline & $(\mu \mathrm{g} / \mathrm{mL})$ & & \multicolumn{1}{c}{ Mean $\pm \mathrm{SD}$} \\
\hline Liposome & Control & & $1.248 \pm 0.007$ \\
& SLS & 25 & $1.219 \pm 0.005^{* * * *}$ \\
& & 50 & $1.215 \pm 0.008^{* * *}$ \\
& & 100 & $1.190 \pm 0.006^{* * *}$ \\
HaCaT keratinocyte & Control & & $0.782 \pm 0.006$ \\
& SLS & 50 & $0.735 \pm 0.005^{* *}$ \\
\hline
\end{tabular}

Alterations in membrane fluidity were estimated using an ESR spin-labeling method with 5-DSA. Concentrations of 5-DSA on spin labeling were $1 \mathrm{mM}$ for liposomes and $10 \mathrm{mM}$ for HaCaT keratinocytes. After incubation with 5-DSA for $30 \mathrm{~min}$ at $37^{\circ} \mathrm{C}$, liposomes and $\mathrm{HaCaT}$ keratinocytes were treated with various concentrations of SLS. Membrane fluidity was evaluated by order parameter $(\mathrm{S})$ calculated from the ESR spectra. Significance; Student t-test, $* * p<0.01, * * * p<0.001$.

membranes. The interaction of SLS with membranes was then evaluated using the ESR spin-labeling method with 5-DSA as the spin-labeling probe. Treatment with SLS resulted in increases of membrane fluidity.

In cells, ROS is mainly generated in the process of mitochondria respiratory chain reactions ${ }^{30)}$ and in the enzymatic reaction of NADPH oxidase ${ }^{31)}$. Increases of intracellular $\mathrm{Ca}^{2+}$ concentration induce ROS generation due to the effects on mitochondria and NADPH oxidase assembly ${ }^{32,33)}$. On the other hand, IL- $1 \alpha$ is stored in cells as a precursor, pro-IL- $1 \alpha$. pro-IL- $1 \alpha$ is secreted from cells after processing by calpain, which is activated by $\mathrm{Ca}^{2+}$. In addition, interleukin-1 receptor-associated kinase-1 (IRAK-1), which is activated by the reaction with IL- $1 \alpha$ receptor and its ligand IL- $1 \alpha$, induces the assembly of NADPH oxidase by recruiting cytosolic units to membrane localized units ${ }^{34)}$.

These results suggest that the action of SLS on ROS generation in HaCaT keratinocytes is as follows: First, SLS increases the intracellular $\mathrm{Ca}^{2+}$ influx due to interactions with cell membranes of $\mathrm{HaCaT}$ keratinocytes and $\mathrm{Ca}^{2+}$ elevates ROS generation in mitochondria and also by the activation of NADPH oxidase. Furthermore, $\mathrm{Ca}^{2+}$ stimulates IL- $1 \alpha$ secretion through the activation of calpain, and the resulting IL- $1 \alpha$ also stimulates ROS generation through IRAK-1 activation.

Generally, rough skin is characterized as morphological alterations with blurred "kime" and scaling, as well as a low water content in the stratum corneum and a high TEWL as skin physiological parameters. Furthermore, as a biological parameter, dry skin, which is an early stage of rough skin, exhibits a higher ratio of IL-1RA and IL- $1 \alpha^{3)}$ and frequently carbonylated proteins in the stratum corneum $^{4)}$. SLS is commonly used to produce artificially rough skin. In the skin, SLS reproduces the characteristics 
Table 3 Effects of various anionic detergents on IL-1 $\alpha$ secretion and intracellular ROS levels of HaCaT keratinocytes.

\begin{tabular}{lcc}
\hline \multicolumn{1}{c}{ Surfactants $(50 \mu \mathrm{g} / \mathrm{mL})$} & $\begin{array}{c}\text { IL-1 } \alpha \\
(\mathrm{pg} / \mathrm{mg} \text { protein })\end{array}$ & $\begin{array}{c}\text { Fold changes of } \\
\text { intracellular ROS }\end{array}$ \\
\cline { 2 - 3 } & Mean $\pm \mathrm{SD}$ & Mean $\pm \mathrm{SD}$ \\
\hline Control & $\mathrm{ND}$ & $1.00 \pm 0.07$ \\
Sodium lauryl ether sulfate & $3.55 \pm 2.37$ & $1.46 \pm 0.14^{* * *}$ \\
SLS & $9.05 \pm 0.82$ & $2.47 \pm 0.25^{* * *}$ \\
Sodium polyoxyethylene (5) lauryl ether carboxylate & $0.77 \pm 0.66$ & $1.41 \pm 0.17^{* * *}$ \\
Sodium polyoxyethylene (11) lauryl ether carboxylate & $2.49 \pm 0.58$ & $1.86 \pm 0.23^{* * *}$ \\
Sodium lauryl phosphate & $\mathrm{ND}$ & $0.92 \pm 0.05$ \\
Lauryl ether phosphate & $0.95 \pm 0.66$ & $1.13 \pm 0.14$ \\
Sodium lauroyl methyl alanine & $\mathrm{ND}$ & $1.19 \pm 0.13^{*}$ \\
Sodium lauroyl methyl taurine & $\mathrm{ND}$ & $1.05 \pm 0.09$ \\
Sodium laurate & $\mathrm{ND}$ & $1.17 \pm 0.09^{*}$ \\
Potassium cocoate and potassium myristate & $\mathrm{ND}$ & $1.10 \pm 0.18$ \\
\hline
\end{tabular}

HaCaT keratinocytes were cultured in the presence of various surfactants at a concentration of $50 \mu \mathrm{g} / \mathrm{mL}$ for $24 \mathrm{~h}$. IL-1 $\alpha$ secreted into the medium by HaCaT keratinocytes was quantified using an IL-1 $\alpha$ ELISA Quantikine kit. Intracellular ROS was measured in HaCaT keratinocytes cultured with DMEM containing various surfactants $(50 \mu \mathrm{g} / \mathrm{mL})$ for $6 \mathrm{~h}$. Protein concentrations were determined using a BCA protein assay Kit. Data on IL-1 $\alpha$ are expressed as quantitative value $(p g)$ per mg protein $(n=5)$. Data on intracellular ROS are expressed as averages and standard deviations of a fold change against the value of control cells $(n=5)$. ND: not detected, Significance; Student t-test $* p<0.05, * * * p<0.001$.

of rough skin at the morphological, physiological and biological levels ${ }^{7}$. The relationship between skin moisture function and carbonylated proteins has been demonstrated. Acrolein-treated human excised skin, which produces carbonylated proteins in the stratum corneum, had a decreased water content in a dose-dependent manner following treatment with acrolein ${ }^{35)}$. These facts indicate the possibility that ROS that is generated intracellularly oxidizes proteins and accumulates carbonylated proteins in the epidermis and also the stratum corneum. The accumulation of carbonylated proteins induces or accelerates the rough skin due to the loss of skin moisture function.

Based on this evidence, we propose that the mechanism for the rough skin induced by SLS is triggered by ROS generation through intracellular $\mathrm{Ca}^{2+}$ influx. At the point of ROS generation, the results indicate that sodium lauryl phosphate has a lower potential to induce rough skin.

\section{CONCLUSION}

SLS stimulated intracellular ROS levels in HaCaT keratinocytes and RHE models, and also increased secretion of IL-1 $\alpha$ from HaCaT keratinocytes. The mechanisms were demonstrated as follows. SLS initially interacts with cell membranes, which results in the elevation of intracellular $\mathrm{Ca}^{2+}$ influx. $\mathrm{Ca}^{2+}$ stimulates the secretion of IL-1 $\alpha$ due to the activation of calpain, and also increases ROS generation. IL- $1 \alpha$ also stimulates ROS generation. From these results, we conclude that the elevation of intracellular ROS levels is one of the cause of SLS-induced rough skin. In addition, our results propose a new approach for evaluation of anionic detergents to avoid detergent-induced skin roughness.

\section{Reference}

1) Rawlings, A.V.; Harding, C.R. Moisturization and skin barrier function. Dermatol. Ther. 17 (Suppl. 1), 43-48 (2004).

2) Elias, P.M. Epidermal lipids, barrier function, and desquamation. J. Invest. Dermatol. 80, 44s-49s (1983).

3) Kikuchi, K.; Kobayashi, H.; Hirao, T.; Ito, A.; Takahashi, H.; Tagami, H. Improvement of mild inflammatory changes of the facial skin induced by winter environment with daily applications of a moisturizing cream. A half-side test of biophysical skin parameters, cytokine expression pattern and the formation of cornified envelope. Dermatology 207, 269-275 (2003). 


\section{T. Mizutani, R. Mori and M. Hirayama et al.}

4) Kobayashi, Y.; Iwai, I.; Akutsu, N.; Hirao, T. Increased carbonyl protein levels in the stratum corneum of the face during winter. Int. J. Cosmet. Sci. 30, 35-40 (2008).

5) Fujita, H.; Hirao, T.; Takahashi, M. A simple and noninvasive visualization for assessment of carbonylated protein in the stratum corneum. Skin. Res. Technol. 13, 84-90 (2007).

6) Fedorova, M.; Bollineni, R.C.; Hoffmann, R. Protein carbonylation as a major hallmark of oxidative damage: update of analytical strategies. Mass Spectrom. Rev. 33, 79-97 (2014).

7) Coquette, A.; Berna, N.; Vandenbosch, A.; Rosdy, M.; De Wever, B.; Poumay, Y. Analysis of interleukin-1alpha (IL-1alpha) and interleukin-8 (IL-8) expression and release in in vitro reconstructed human epidermis for the prediction of in vivo skin irritation and/or sensitization. Toxicol. In Vitro 17, 311-321 (2003).

8) Misery, L.; Loser, K.; Ständer, S. Sensitive skin. J. Eur. Acad. Dermatol. Venereol. 30 (Suppl. 1), 2-8 (2016).

9) Dontchev, V.D.; Letourneau, P.C. Nerve growth factor and semaphorin 3A signaling pathways interact in regulating sensory neuronal growth cone motility. J. Neurosci. 22, 6659-6669(2002).

10) Tominaga, M.; Ozawa, S.; Tengara, S.; Ogawa, H.; Takamori, K. Intraepidermal nerve fibers increase in dry skin of acetone-treated mice. J. Dermatol. Sci. 48, 103-111 (2007).

11) Aramaki, J.; Kawana, S.; Effendy, I.; Happle, R.; Löffler, H. Differences of skin irritation between Japanese and European women. Br. J. Dermatol. 146, $1052-$ 1056 (2002).

12) Hoffman, D.R.; Kroll, L.M.; Basehoar, A.; Reece, B.; Cunningham, C.T.; Koenig, D.W. Immediate and extended effects of sodium lauryl sulphate exposure on stratum corneum natural moisturizing factor. Int. J. Cosmet. Sci. 36, 93-101 (2014).

13) Nardo, A.D.; Sugino, K.; Wertz, P.; Ademola, J.; Maibach, H.I. Sodium lauryl sulfate (SLS) induced irritant contact dermatitis: a correlation study between ceramides and in vivo parameters of irritation. Contact Dermatitis 35, 86-91 (1996).

14) Törmä, H; Lindberg, M; Berne, B. Skin barrier disruption by sodium lauryl sulfate-exposure alters the expressions of involucrin, transglutaminase 1, profilaggrin, and kallikreins during the repair phase in human skin in vivo. J. Invest. Dermatol. 128, 1212-1219 (2008).

15) Mao, G.; Flach, C.R.; Mendelsohn, R.; Walters, R.M. Imaging the distribution of sodium dodecyl sulfate in skin by confocal Raman and infrared microspectroscopy. Pharm. Res. 29, 2189-2201 (2012).

16) Cohen, C.; Dossou, G.; Rougier, A.; Roguet, R. Measurement of inflammatory mediators produced by hu- man keratinocytes in vitro: a predictive assessment of cutaneous irritation. Toxicol. Vitr. 5, 407-410(1991).

17) Gibbs, S.; Vietsch, H.; Meier, U.; Ponec, M. Effect of skin barrier competence on SLS and water-induced IL-1 $\alpha$ expression. Exp. Dermatol. 11, 217-223 (2002).

18) Negre-Salvayre, A.; Coatrieux, C.; Ingueneau, C.; Salvayre, R. Advanced lipid peroxidation end products in oxidative damage to proteins. Potential role in diseases and therapeutic prospects for the inhibitors. $\mathrm{Br}$. J. Pharmacol. 153, 6-20 (2008).

19) Boukamp, P.; Petrussevska, R.T.; Breitkreutz, D.; Hornung, J.; Markham, A.; Fusenig, N.E. Normal keratinization in a spontaneously immortalized aneuploid human keratinocyte cell line. J. Cell Biol. 106, 761-771 (1988).

20) Nakano, M. Assay for superoxide dismutase based on chemiluminescence of luciferin analog. Methods Enzymol. 186, 227-232 (1990).

21) Guttmann, R.P.; Sokol, S.; Baker, D.L.; Simpkins, K.L.; Dong, Y.; Lynch, D.R. Proteolysis of the N-methyl-daspartate receptor by calpain in situ. J. Pharmacol. Exp. Ther. 302, 1023-1030(2002).

22) Dolak, J.A.; Waller, R.L.; Glende, E.A.Jr.; Recknagel, R.O. Liver cell calcium homeostasis in carbon tetrachloride liver cell injury: new data with fura2. J. Biochem. Toxicol. 3, 329-342 (1988).

23) Hubbell, W.L.; McConnell, H.M. Molecular motion in spin labeled phspholipids and membranes. J. Am. Chem. Soc. 93, 314-326(1971).

24) Kitagawa, S.; Kametani, F.; Tsuchiya, K.; Sakurai, H. ESR analysis with long-chain alkyl spin labels in bovine blood platelets. Relationship between the increase in membrane fluidity by alcohols and phenolic compounds and their inhibitory effects on aggregation. Biochim. Biophys. Acta 1027, 123-129 (1990).

25) Bangham, A.D.; Standish, M.M.; Watkins, J.C. Diffusion of univalent ions across the lamellae of swollen phospholipids. J. Mol. Biol. 13, 238-252(1965).

26) Sultana, T.; Wahab-Wahlgren, A.; Assmus, M.; Parvinen, M.; Weber, G.; Söder, O. Expression and regulation of the prointerleukin-1alpha processing enzymes calpain I and II in the rat testis. Int. J. Androl. 26, 37-45 (2003).

27) Dormer, R.L. Introduction of calcium chelators into isolated rat pancreatic acini inhibits amylase release in response to carbamylcholine. Biochem. Biophys. Res. Commun. 119, 876-883(1984).

28) Clemens, R.A.; Lowell, C.A. Store-operated calcium signaling in neutrophils. J. Leukoc. Biol. 98, 497-502 (2015).

29) Elsholz, F.; Harteneck, C.; Muller, W.; Friedland, K. Calcium-a central regulator of keratinocyte differentiation in health and disease. Eur. J. Dermatol. 24, 650661 (2014). 
30) Richter, C.; Gogvadze, V.; Laffranchi, R.; Schlapbach, R.; Schweizer, M.; Suter, M.; Walter, P.; Yaffee, M. Oxidants in mitochondria: from physiology to diseases. Biochim. Biophys. Acta 1271, 67-74(1995).

31) Gamaley, I.A.; Klyubin, I.V. Roles of reactive oxygen species: signaling and regulation of cellular functions. Int. Rev. Cytol. 188, 203-255(1999).

32) Santo-Domingo, J.; Wiederkehr, A.; De Marchi, U. Modulation of the matrix redox signaling by mitochondrial $\mathrm{Ca}^{2+}$. World J. Biol. Chem. 6, 310-323(2015).

33) Valencia, A.; Kochevar, I.E.; Nox1-based NADPH oxidase is the major source of UVA-induced reactive oxy- gen species in human keratinocytes. J. Invest. Dermatol. 128, 214-222 (2008).

34) Maitra, U.; Singh, N.; Gan, L.; Ringwood, L.; Li, L. IRAK-1 contributes to lipopolysaccharide-induced reactive oxygen species generation in macrophages by inducing NOX-1 transcription and Rac1 activation and suppressing the expression of antioxidative enzymes. J. Biol. Chem. 284, 35403-35411 (2009).

35) Iwai, I.; Hirao, T.; Protein carbonyls damage the waterholding capacity of the stratum corneum. Skin Pharmacol. Physiol. 21, 269-273(2008). 